\title{
Summers depois de Hansen? Comparação das explicações convencionais e não convencionais acerca da estagnação nas economias avançadas
}

\author{
Summers after Hansen? Comparison of \\ conventional and nonconventional explanations \\ for stagnation in advanced economies
}

ASSILIO LUIZ ZANELLA DE ARAUJO*

\begin{abstract}
RESUMO: O presente artigo apresenta e compara as explicações convencionais e não convencionais acerca da estagnação nas economias avançadas. Enquanto as primeiras atribuem a insuficiência crônica de demanda a uma nova rigidez das economias, o keynesianismo-estruturalista a considera resultado da implementação das políticas econômicas neoliberais e da destruição das instituições do período pós-Segunda Guerra. A explicação marxista em tela, ainda que não negligencie o impacto negativo destas políticas, enxerga esse problema como decorrente da formação dos grandes oligopólios internacionais. Em virtude das semelhanças e possível complementaridade, consideramos que uma maior aproximação entre as correntes keynesiano-estruturalista e marxista seria benéfica a ambas. PALAVRAS-CHAVE: Estagnação; explicações convencionais; marxismo e keynesianismoestruturalista.
\end{abstract}

ABSTRACT: This article aims at presenting and contrasting the conventional and nonconventional explanations for economic stagnation in advanced economies. While conventional explanations impute to a new rigidity of these economies the chronic insufficiency of demand, Structural Keynesianism sees this as the result of the neoliberal economic policies and the destruction of the post-World War II institutions. Marxist explanation, even though do not neglect the negative impact of these policies, perceives this problem as resulting from the formation of the great international oligopolies. Due to similarities and possible complementarity, we think that an approximation between Structural Keynesianism and Marxism would be beneficial to both.

KEYWORDS: Stagnation; conventional explanations; Marxism and Structural Keynesianism. JEL Classification: B50; E60; O11.

\footnotetext{
* Doutorando em Economia do Desenvolvimento na Universidade Federal do Rio Grande do Sul/UFRGS, RS - Brasil. E-mail assilioaraujo@hotmail.com. Submetido: 26/Fevereiro/2018; Aprovado: 28/Março/2018.
} 


\section{INTRODUÇÃO}

Em novembro de 2013, o ex-secretário do Tesouro dos Estados Unidos Lawrence H. Summers impressionou, na Conferência Anual do FMI, ao questionar se as ideias sob o termo "estagnação secular" (formuladas pioneiramente por Alvin H. Hansen pós-Grande Depressão) não seriam importantes para entender a experiência das economias avançadas, em frente à dificuldade destas para atingir o crescimento potencial, não obstante todas as medidas de estímulo adotadas desde a crise financeira de 2007-2008 ${ }^{1}$.

Hansen, conhecido como grande seguidor das ideias de Keynes na América², popularizou o conceito "estagnação secular" em um trabalho, solicitado pelo presidente Franklin D. Roosevelt, sobre as razões da desaceleração abrupta da economia norte-americana em 1937, após alguns anos de recuperação do crash de 1929. Neste documento, intitulado "Economic Progress and Declining Population Growth", posteriormente publicado em uma revista acadêmica de alto impacto, Hansen afirma que o mundo ocidental estava passando por uma transformação estrutural de grande monta não menos importante do que as mudanças associadas à revolução industrial, transitando de uma "great era of growth and expansion of the nineteenth century from an era which no man, unwilling to embark on pure conjucture, can as yet characterize with clarity or precision" $(1939$, p. 1). Para ele, as razões dessa transformação, no caso específico dos Estados Unidos, eram basicamente três:

(a) inventions, (b) the discovery and development of new territory and new resources, and (c) the growth of population. Each of these in turn, severally and in combination, has opened investment outlets and caused a rapid growth of capital formation (Hansen, 1939, p. 3).

Como nenhum destes fatores apresentaria no século XX o mesmo dinamismo observado no século anterior, a previsão do autor era que a formação de capital

${ }^{1} \mathrm{O}$ discurso de Summers encontra-se disponível no YouTube: https://www.youtube.com/ watch? $v=K Y p V z B b Q I X 0$. E a transcrição do discurso pode ser encontrada na página pessoal de Summers: http://larrysummers.com/imf-fourteenth-annual-research-conference-in-honor-of-stanleyfischer/.

\footnotetext{
${ }^{2}$ Keynes reconheceu a possibilidade de uma economia ficar abaixo do equilíbrio de pleno emprego dos fatores produtivos por um longo período. Na Teoria Geral do Emprego, do Juro e da Moeda, escreve o pensador inglês: “[...] é uma das características essenciais do sistema econômico em que vivemos [...] permanecer em condições crônicas de atividade subnormal durante um tempo considerável sem tendência marcada para a recuperação ou colapso completo" (1936, p. 194). Contudo, Hansen não associava a ideia de estagnação secular à obra de Keynes, argumentando que ele tratou das questões "institucionais" e "psicológicas" do investimento, mas havia deixado de lado os fatores "reais", tais como o crescimento populacional e o progresso técnico (Backhouse e Boianovsky, 2016). Em seu verbete "stagnation", no The New Palgrave Dictionary of Economics, Steindl pontua que: "In fact, there are occasional glimpses of stagnation in the General Theory and more so in Harrod's and Joan Robinson's work" (1987, p. 473).
} 
iria cair aproximadamente pela metade nesse período que se iniciava, levando, na ausência de uma revolução tecnológica comparável à que causou o surto de investimentos associados à construção de rodovias ou, posteriormente, à produção de automóveis e aos desenvolvimentos em termos de infraestrutura impulsionados por essa indústria, a um estado de depressão prolongado, com um desemprego alto e praticamente imóvel ${ }^{3}$.

Como mostram Backhouse e Boianovsky (2016), com base no número de artigos no JSTOR que mencionavam o termo "estagnação secular", a tese ganhou rapidamente popularidade ao longo dos anos 1940. Naquele contexto não faltavam razões que justificassem esse pessimismo: com o fim da Segunda Guerra Mundial, os Estados Unidos desmobilizariam mais de 11 milhões de soldados das forças armadas, e havia aproximadamente mais 9 milhões empregados nas "indústrias de defesa" que seriam dispensados, totalizando 21 milhões de desempregados potenciais em um mercado de trabalho de cerca de 60 milhões (Fogel, 2005). Porém, o receio em torno de uma possível paralisia da economia nos anos seguintes e de um desemprego maciço mostraram-se falsos e a economia norte-americana, após uma curta recessão no final da Guerra, iniciou um período de expansão sem precedentes. Nas décadas subsequentes a Europa e o Japão seguiriam o mesmo caminho. Consequentemente, com a prosperidade do período pós-Guerra esqueceu-se, como é natural ocorrer, o trauma da depressão dos anos 1930, e a discussão a respeito da possibilidade de "estagnação secular" praticamente desapareceu do mainstream da economia.

Alguns autores heterodoxos, notadamente Josef Steindl (1952) e Paul A. Baran e Paul Sweezy (1966), publicaram trabalhos importantes sobre o tema, mas que receberam pouca atenção por parte do core da profissão, seja por conta do período de prosperidade que vivia o capitalismo, seja pelas implicações radicais que traziam em seu bojo. Mais recentemente, Foster e Magdoff (2009) e Foster e McChesney (2012) procuraram dar continuidade ao trabalho destes autores, analisando a crise financeira de 2007-2008 e a Grande Recessão. De outro lado, a partir de uma vertente teórica mais próxima de Keynes e Minsky, Palley (2009, 2012) é outro autor heterodoxo que buscou (antes de Summers) chamar a atenção para o problema de estagnação que cerca as economias centrais. $\mathrm{Na}$ introdução do seu livro From Financial Crisis to Stagnation, Palley assinala:

[...] the Great Recession will be followed by a Great Stagnation during which the unemployment rate will remain high, wages will stagnate, and a general sense of economic disquiet will prevail. [...] This is not a tight numeric forecast, but rather a prediction about directional tendency based on current economic policies in the United States and other

\footnotetext{
3 “This is the essence of secular stagnation - sick recoveries which die in their infancy and depressions which feed on themselves and leave a hard and seemingly immovable core of unemployment" (Hansen, 1939, p. 4).
} 
countries. There will undoubtedly be months when the news is good and months when it is bad, but the general tendency will be one of stagnation and failure to recover shared prosperity. Growth will continue, but it will be growth with unnecessary high unemployment. Moreover, growth will be slower than what could be achieved in a full-employment economy (2012, p. 3, grifo nosso).

No entanto, essas interpretações não são mencionadas na literatura convencional sobre "estagnação secular". Nesta, Hansen aparece como pioneiro dessa discussão e Summers reinaugurando-a, após um "vácuo" que durou mais de sete décadas. Por isso, questiona-se provocativamente no título deste trabalho "Summers depois de Hansen?".

Nesse contexto, o presente artigo apresenta e compara as explicações convencionais e não convencionais em torno da estagnação nas economias avançadas. Duas são as perspectivas heterodoxas abordadas (já mencionadas acima): a visão keynesiano-estruturalista desenvolvida por Thomas Palley e a tradição marxista ligada à Monthly Review, assentada na tese do "Capital Monopolista". Do lado das explicações que denominamos de convencionais, dar-se-á mais atenção aos trabalhos de Robert J. Gordon e Lawrence H. Summers, em virtude de serem os mais divulgados e debatidos e representarem os dois lados das teses dominantes dentro do mainstream ${ }^{4}$.

Cabe destacar que se pretende apenas resenhar o debate a respeito da "estagnação secular" no seu sentido restrito, não discutindo, portanto, a literatura mais ampla sobre a queda tendencial da taxa de lucro e a estagnação do capitalismo, que tem origem no pensamento clássico e é parte central da teoria econômica marxista ${ }^{5}$.

Nas seções subsequentes apresentam-se as teses convencionais e não convencionais sobre o tema, além das proposições de política econômica delas decorrentes. As considerações finais sintetizam as principais conclusões.

\section{EXPLICAÇÕES CONVENCIONAIS}

Após o pronunciamento de Summers em 2013, a tese da "estagnação secular" passou novamente a ser tema de debate entre economistas e formuladores de política, dando origem a diferentes explicações para o estado de prostração das economias capitalistas avançadas.

When late last year, former US treasury secretary Lawrence Summers suggested that the advanced economies, and the US in particular,

\footnotetext{
${ }^{4}$ Ver parte inicial da segunda seção.

${ }^{5}$ Para uma breve porém elucidativa discussão dessa questão segundo a tradição marxista, ver a resenha de Bresser-Pereira (2018).
} 
might be suffering from "secular stagnation," his remarks struck a chord. The idea that the US and the other advanced economies might be suffering from more than the hangover from a financial crisis resonated with many observers (Eichengreen, 2014, p. 41).

As principais abordagens convencionais foram compiladas no livro editado por Teulings e Baldwin (2014). Para estes autores, elas podem ser organizadas em três vertentes. Uma primeira, segundo eles, firmemente keynesiana com todos os seus "refinamentos" modernos, de acordo com a qual há uma insuficiência crônica de demanda e o problema, portanto, é que o produto permanecerá constantemente abaixo do produto potencial. Uma segunda, que foca nos fatores do lado da oferta à la Solow-Romer, e aponta como principal questão a queda do produto potencial, por conta de um menor crescimento da produtividade dos fatores e do próprio crescimento destes insumos. $\mathrm{E}$ ainda uma terceira vertente que enfatiza o dano permanente que a crise pode ter no nível de produto da economia, tendo como referência a literatura sobre histerese do mercado de trabalho, que aponta para a perda em termos de emprego após uma recessão, em função, por exemplo, da depreciação que o capital humano pode sofrer fora do trabalho. Como esta última tese é a menos desenvolvida e divulgada das três e, na verdade, parece se tratar de um fenômeno diferente pois coloca a estagnação não como resultado de fatores estruturais (de longo prazo), mas como consequência da crise financeira, analisaremos mais detidamente apenas as duas primeiras, referindo-nos simplesmente a teses do lado da oferta (segunda) e do lado da demanda (primeira).

No tocante à oferta, Gordon (2012, 2014a, 2014b) expõe um duplo problema para a economia Norte-americana. Por um lado, o crescimento da produtividade sofreu um declínio a partir do último quarto do século passado em relação ao período 1891-1972, e tende a permanecer nesse ritmo nos próximos anos. A explicação para esse menor crescimento da produtividade está no caráter multidimensional da Segunda Revolução Industrial e na sua capacidade de continuar impulsionando inovações e melhorias em diversas áreas (que continuaram acontecendo até aproximadamente 1970) vis-à-vis o caráter mais específico ou unidimensional da Terceira Revolução Industrial que, não obstante tenha gerado inovações impressionantes (internet, e-mail, smartphones, etc.), não tem a mesma capacidade de encadeamento de sua antecessora. Ademais, e talvez este seja o ponto mais polêmico de tese de Gordon, o autor é cético em relação ao impacto em termos de produtividade das futuras invenções como robôs, impressoras 3D, big data, etc., quando comparado com as transformações radicais que ocorreram principalmente de 1920 a 1970.

Por outro lado, Gordon aponta uma série de "headwinds" que estão deprimindo a capacidade de crescimento dos Estados Unidos e tendem a continuar agindo nas próximas décadas. Para ele, os principais ventos contrários são os seguintes: a) menor número de horas trabalhadas per capita, por conta seja da aposentadoria da geração baby boom seja da saída de jovens do mercado de trabalho; b) a estagnação da contribuição da educação para o crescimento da produtividade das EUA, ajudado tanto pela queda deste país nos rankings relativos à qualidade da educação básica quanto 
pelos menores percentuais de jovens que completam a universidade; $c$ ) o claro crescimento da desigualdade, resultando em um crescimento da renda real dos $99 \%$ ainda menor do que da média total da população; e d) uma projeção de aumento da relação dívida/PIB para todos os níveis de governo, o que levará inevitavelmente a elevação da tributação e uma redução do crescimento das transferências de renda. Esses fatores somados estão retirando 1,2 ponto percentual dos $2 \%$ de crescimento anual do PIB per capita verificado entre 1891 e 2007. Como posto acima, o resultado está sendo ainda pior para os estratos inferiores na distribuição de renda, uma vez que a renda deles é a mais afetada. Com base nisso, a conclusão principal do autor é que, como os headwinds são específicos e, portanto, afetam de forma diferente as economias avançadas, o padrão de vida nos Estados Unidos diminuirá nas próximas décadas e como consequência outras economias o ultrapassarão.

Summers, por sua vez, não acredita que o problema principal esteja do lado da oferta, uma vez que a inflação está baixa em quase todos os países desenvolvidos. Além disso, se há algum problema nesse sentido, não foi causado por fatores exógenos, como apontado por Gordon, e sim pela insuficiência de demanda, que cria a oferta futura. Para Summers, o baixo crescimento nos Estados Unidos (o mesmo argumento vale, segundo ele, para a Europa e para o Japão) pode ser explicado por mudanças estruturais na economia que levaram a uma alteração no equilíbrio entre poupança e investimento, causando um declínio da taxa natural de juros compatível com o pleno emprego dos fatores produtivos. Assim, em um ambiente de inflação baixíssima, as autoridades econômicas se veem impossibilitadas de levar a taxa real de juros para esse novo equilíbrio, em virtude do Zero Lower Bound (ZLB). Nas palavras de Summers (2014a, pp. 31-32):

Suppose that a substantial shock took place [...] and this tended to raise private savings propensities and reduce investment propensities. How would growth be affected? The normal answer to this question is that one would expect interest rates to fall (driven either by market forces or policy actions) until the saving and investment rate were equated at the full-employment level of output. [...] But this presupposes full flexibility of interest rates. In fact, in modern economies short-term safe interest rates cannot fall appreciably below zero because of the possibility of currency substitution. So interest rates are not fully flexible in modern economies.

Na verdade, esse argumento não é original: Krugman (1998) já o havia utilizado para analisar o caso do Japão nos anos 1990 e Eggerstsson e Krugman (2012) usam o ZLB para explicar a recessão pós-crise financeira, sem, contudo, chamar a atenção para a "estagnação secular" 6 .

\footnotetext{
${ }^{6}$ Uma terceira variação desse argumento, além de Summers e Krugman, é a hipótese do "global saving glut", associada principalmente a Bernanke, de acordo com a qual existiria um excesso de poupança que seria direcionado para os Estados Unidos, aumentando a oferta de fundos emprestáveis neste país
} 
Summers (2014a, 2014b, 2015, 2016) cita alguns fatores como possíveis “culpados" por essa mudança do equilíbrio entre poupança e investimento, quais sejam:

a. redução da demanda por investimentos financiados por dívidas. Isso, em parte, ocorreu por conta do período de excessiva alavancagem e da maior restrição sobre os bancos que surgiu em virtude disso. Mas também, e principalmente, como reflexo de uma mudança no caráter da atividade econômica produtiva, que pode ser vista, por exemplo, na redução significativa do montante necessário para se iniciar um novo empreendimento ou no fato de empresas com um volume relativamente baixo de capital investido, principalmente do ramo de tecnologia e novas mídias, terem um valor de mercado superior a empresas "tradicionais";

b. lembrando o argumento original de Hansen (1939), uma queda na taxa de crescimento populacional, diminuindo a necessidade de novos investimentos para atender à demanda;

c. mudanças na distribuição de renda, favorecendo tanto o capital em detrimento do trabalho quanto os com mais riqueza em detrimento daqueles com menos riqueza. Além disso, há um aumento dos lucros retidos das corporações. Todas essas mudanças operam no sentido de um aumento da propensão a poupar;

d. redução do preço relativo dos bens de capital, o que significa o mesmo investimento pode ser executado com menos empréstimo e menos gasto;

e. em linha com o argumento do "global saving glut", um movimento global (especialmente entre as economias em desenvolvimento) em direção a ativos mais seguros, em particular a títulos do Tesouro norte-americano, o que contribui para reduzir a taxa de juros de equilíbrio nos países centrais.

Rachel e Smith (2015) testaram cada um desses fatores e concluíram que as mudanças nas preferências de poupança e investimento foram responsáveis por 300 pontos base da queda de 450 pontos base da taxa natural de juros desde 1980 . Outros 100 pontos base podem ser explicados, de acordo com estes economistas do Banco da Inglaterra, pelas mudanças nas perspectivas de crescimento após a crise financeira mundial, contribuindo para isso fatores demográficos e os headwin$d s$ mencionados por Gordon. Embora os autores trabalhem com uma estimativa de uma taxa de juros "global", eles argumentam que esta taxa pode ser pensada

e reduzindo a taxa de juros compatível com o pleno emprego. Como enfatizado por Palley (2016), todos esses argumentos trabalham com a ideia pré-keynesiana de que existe um mercado de fundos emprestáveis, onde a taxa de juros é a variável que equilibra poupança e investimento. Essa ideia, apesar de ter seduzido Keynes nos seus primeiros trabalhos, foi totalmente descartada por ele em sua Teoria Geral, sendo substituída pela teoria da preferência pela liquidez. Portanto, Palley (2016) pontua, com razão, o que ele chama de $Z L B$ economics é estranha à teoria de Keynes tal como exposta em seus principais trabalhos, sendo mais uma nova versão do modelo novo-keynesiano (na verdade, prékeynesiano), que adiciona como sua mais nova rigidez não os preços e salários e sim a ZLB. Para uma crítica teórica e empírica desse modelo, ver também Taylor (2014, 2016). 
como uma âncora para a qual todas as taxas de juros de equilíbrio convergem no longo prazo e, por conseguinte, pode ser utilizada como um importante insumo para calibrar a política monetária.

No que diz respeito às políticas econômicas, as respostas variam dependendo de quais fatores são enfatizados para explicar a situação atual e as perspectivas deprimidas de crescimento para o futuro. Para aqueles que privilegiam o lado da oferta, a resposta está nas chamadas reformas estruturais que procuram aumentar o produto potencial das economias, tais como: melhorar o sistema educacional; remover as barreiras para a mobilidade do trabalho entre as firmas por meio da flexibilização da legislação trabalhista; aumentar os incentivos para que trabalhadores pouco qualificados participem do mercado de trabalho; simplificar o procedimento para abertura de novos negócios; e ampliar as políticas antitruste para reduzir as margens de lucro nas novas indústrias (Teulings e Baldwin, 2014). ${ }^{7}$

Para as teses do lado da demanda, em contraste, reformas estruturais, apesar de importantes, podem ser contraproducentes para resolver o problema de "estagnação secular”, uma vez que um aumento da oferta à frente da demanda resultaria em menos inflação e, por conseguinte, em maior dificuldade para atingir a taxa de juros de equilíbrio (Summers, 2015). Neste contexto, o melhor seria, segundo eles, utilizar os instrumentos de política macroeconômica a fim de aumentar a demanda a qualquer nível de taxa de juros, aumentando, dessa forma, o nível de produto consistente com uma maior taxa de juros de equilíbrio. Para isso, a política monetária parece ser de importância secundária, uma vez que, além da reduzida eficácia que uma redução adicional da taxa de juros (ou mesmo uma utilização ainda mais ampla de instrumentos não convencionais de política monetária) teria em termos de estímulo ao investimento nessa situação, há implicações importantes em termos de instabilidade financeira relacionadas a esses instrumentos. Desse modo, fica a cargo da política fiscal, e mais particularmente do investimento público, a tarefa de retirar as economias desse estado de semidepressão permanente.

\section{EXPLICAÇÕES ALTERNATIVAS}

As abordagens alternativas para a explicação da estagnação prolongada nas economias capitalistas avançadas foram divididas, neste trabalho, em duas grandes

\footnotetext{
${ }^{7}$ Gordon, porém, é bastante cético em relação à possibilidade de as autoridades conseguirem reverter essa situação: "There is little that politicians can do about it. My standard list of policy recommendations includes raising the retirement age in line with life expectancy, drastically raising the quotas for legal immigration, legalising drugs and emptying the prisons of non-violent offenders, and learning from Canada how to finance higher education. The US would be a much better place with a medical system as a right of citizenship, a value-added tax to pay for it, a massive tax reform to eliminate the omnipresent loopholes, and an increase in the tax rate on dividends and capital gains back to the 1993-97 Clinton levels. [...] But hypothetical legislation, however politically improbable, has its limits. The headwinds that are slowing the pace of the US's future economic growth have been decades in the making, entrenched in many aspects of our society" (2014, pp. 57-58).
} 
vertentes: uma primeira que chamamos, seguindo Thomas I. Palley, de Keynesianismo-estruturalista. Essa interpretação se diferencia da abordagem pós-keynesiana, e, por isso, o termo "estruturalista", por chamar a atenção para os desenvolvimentos do lado "real" da economia, procura conciliar a análise dos aspectos financeiros (enfatizados por Keynes e Minsky) com uma visão atenta para os fatores institucionais e estruturais da economia capitalista. Nesse sentido, não obstante não negue a análise minskyana (e o foco que ela concede à questão da instabilidade financeira ${ }^{8}$ ), aproximar-se-ia mais de outras abordagens heterodoxas como a interpretação de Estruturas Sociais de Acumulação de $\operatorname{Kotz}(2003,2009)$ e a tradição marxista ligada à Monthly Review ${ }^{9}$.

Apesar de haver outras interpretações marxistas que compartilham da ideia que os países capitalistas avançados vivenciarão um período de baixo crescimento nos próximos anos, utilizou-se como referências principais, para a segunda parte desta seção, os trabalhos de Foster e Magdoff (2009) e Foster e McChesney (2012), além de artigos desses autores (e de outros) na Monthly Review, por essa abordagem estar mais relacionada à ideia de uma tendência "estagnacionista" do capitalismo. Para esses autores, assim como para Sweezy e Baran, a estagnação é o estado normal do sistema, sendo os períodos de crescimento a sua exceção ou o resultado de fatores externo a ele. Além do mais, como bem observado por Palley, há pontos de intersecção importantes entre a análise keynesiano-estruturalista e essa tradição marxista, o que não é verdade para interpretações marxistas mais ortodoxas. Dessa maneira, é possível, suplementarmente, extrair algumas semelhanças e diferenças entre essas análises.

\section{Keynesianismo-estruturalista}

A interpretação keynesiano-estruturalista inicia sua narrativa da tendência à estagnação nos países capitalistas avançados no início dos anos 1980, mais especificamente na ascensão de governos neoliberais nos Estados Unidos e na Grã-Bretanha (Ronald Reagan assumiu o governo dos Estados Unidos pela primeira vez em 1981, ao passo que Margaret Thatcher tornou-se primeira-ministra britâ-

\footnotetext{
${ }^{8}$ Muito pelo contrário. Ver, por exemplo, Palley (2010), onde ele enfatiza a importância de interpretação de Minsky para a explicação da crise financeira recente, mas considera que há limites nessa análise para entender a situação das economias capitalistas avançadas, postos exatamente pela negligência dos aspectos estruturais. Sem eles, por exemplo, não fica claro por que as bolhas de ativos, e mais especificamente a bolha do mercado imobiliário norte-americano, foi condição necessária para que as economias continuassem crescendo, ainda que bem abaixo do seu potencial. Palley, inclusive, assinala que Minsky procurou corrigir essa ausência em um trabalho com a ideia (não muito conhecida) de superciclos minskyanos, que seriam, segundo Palley, ciclos financeiros de longo prazo, onde há uma atenção sobre as transformações institucionais da economia.

${ }^{9}$ Essa linha de interpretação marxista está principalmente vinculada aos nomes de Paul Sweezy (cofundador e editor da Monthly Review) e Paul A. Baran, que escreveram o livro Capital Monopolista, e Harry Magdoff, também editor da referida revista por décadas. Atualmente, o editor da Monthly Review, e continuador das ideias de Sweezy e Baran, é John Bellamy Foster.
} 
nica em 1979). Para Palley (2012), essa mudança marca a transformação do caráter dos ciclos econômicos nestes países e da própria prioridade das políticas econômica. Se durante todo o período pós-guerra até o início dos anos 1980 a política econômica tinha como prioridade central o pleno emprego e, do ponto de vista estrutural, os salários cresciam junto com produtividade, a partir desse período, o principal foco em termos de política econômica torna-se a estabilidade de preços e o crescimento dos salários fica recorrentemente abaixo do incremento da produtividade.

Desse modo, quebra-se o ciclo virtuoso que acompanhou essas economias durante a chamada era do ouro do capitalismo, qual seja, o crescimento da produtividade puxava o crescimento dos salários, que, por sua vez, estimulava a demanda agregada e gerava uma situação de pleno emprego; isso encorajava novos investimentos que resultava em maior incremento da produtividade. Com o fim desse ciclo, criou-se um "buraco" no "processo gerador de demanda", que foi parcialmente preenchido pela inflação dos ativos (o efeito-riqueza vinculado a ela) e pelo aumento brutal do endividamento dos agentes ${ }^{10}$.

Antes de entrar propriamente no modo de funcionamento desse novo ciclo neoliberal, é importante entender exatamente como se formou esse "buraco" no processo gerador de demanda, pois está nele a chave para a compreensão da tendência à estagnação dessas economias. De acordo com Palley (2009), houve um duplo processo de atrofiamento do lado da demanda da economia. Por um lado, um processo interno das economias (já parcialmente explicado acima), onde as políticas econômicas tiveram um papel central. Palley (2013b) utiliza, metaforicamente, uma imagem de uma caixa para explicar o regime de política econômica implementado a partir dos anos 1980, onde os trabalhadores ficam no centro dessa caixa e são pressionados por todos os lados.

A primeira fonte de pressão vem da globalização, mais particularmente de um modelo específico de globalização que estimula o livre comércio e a livre mobilidade de capitais (este ponto será desenvolvido a seguir, pois se refere mais diretamente ao outro lado desse processo de enfraquecimento da demanda). A segunda fonte, segundo Palley (2009), está relacionada à ideologia do estado mínimo, que mina a legitimidade das políticas públicas e estimula a privatização e a desregula-

\footnotetext{
${ }^{10}$ Palley se refere diversas vezes ao longo dos trabalhos ao que ele chama de "processo gerador de demanda" e o "enfraquecimento" do mesmo com a implementação das políticas e instituições neoliberais. No trecho a seguir ele explica o seu significado (a ideia central é que se trata de algo estrutural, e não de uma insuficiência de demanda efetiva causada por fatores temporários ou conjunturais): "Structural Keynesianism adds additional concerns with underlying 'demand generating process', which is the product of the economic system. Its process perspective is dynamic and is also concerned with income distribution. Recessions can be due to temporary declines in private-sector demand, but they can also be due to failings in the underlying demand-generating process. If the system is faulty, it can suffer from persistent lack of demand. In this event, the economy will experience prolonged stagnation and even depression as happened in the 1930s and may now be happening again. It is this idea of "systemic" versus "temporary" demand shortage that distinguishes structural Keynesianism from textbook Keynesianism” (Palley, 2012, p. 16).
} 
mentação da economia. Isso levou à erosão dos direitos dos trabalhadores, bem como à debilitação da capacidade administrativa do Estado, que terceirizou grande parte de suas funções para corporações. $O$ terceiro ponto é a chamada flexibilização do mercado de trabalho, que envolve o ataque aos sindicatos, à legislação do salário-mínimo, aos benefícios dos desempregados e às proteções do emprego e direitos dos empregados. A justificativa para isso foi o alegado elo entre maior flexibilidade do mercado de trabalho, inclusive dos salários, e o aumento do número de pessoas empregadas. Por fim, mas não menos importante, o abandono do pleno emprego como uma das prioridades das políticas econômicas, e a promoção do controle da inflação para o posto de principal meta das autoridades monetárias. Segundo Palley (2009, 2012, 2013b), essa transição é levada a efeito dentro da ciência econômica pela ideia de taxa natural de desemprego de Milton Friedman, que estabelece o fim do trade-off entre desemprego e inflação no longo prazo.

Por outro lado, a forma de engajamento dos Estados Unidos na globalização também contribuiu para desgastar o "processo gerador de demanda". Palley cita três marcos nesse processo, a saber: a implementação do Acordo de Livre Comércio da América do Norte (Nafta), a adoção de uma política de dólar forte após a crise dos países asiáticos em 1997 e o estabelecimento de relações comerciais normais com a China a partir de 2000, com a sua participação na Organização Mundial do Comércio $(\mathrm{OMC})$. Esses três acontecimentos agiram no mesmo sentido de, por um lado, facilitar a entrada de produtos importados mais baratos nos Estados Unidos e, por outro, promover a operação de empresas norte-americanas em outros lugares do mundo. Isso gerou um "vazamento" da demanda da economia norte-americana para outros países, bem como uma transferência dos empregos e de novos investimentos para esses locais. Como resultado, além de deprimir a demanda interna, esse processo pressionou ainda mais o rendimento dos trabalhadores norte-americanos, uma vez que se viram expostos, a partir de então, à concorrência de trabalhadores de outros países com a média salarial bastante inferior a nacional. Não obstante, essa forma de engajamento na globalização contava com certo apoio da população norte-americana, pois garantia a entrada de produtos importados baratos, cobrindo parte da perda do salário real decorrente desse modelo de concorrência global "race to the bottom".

Esse modelo já mostrava seus sinais de esgotamento nos anos 1990, como na recuperação sem a geração normal de emprego ("jobless recovery”) após o encerramento do ciclo de negócios desse período. Porém, a ampla desregulamentação financeira, que ganha força nessa época, e as inovações nesse mercado permitiram que, inconscientemente, a "hemorragia" do lado da demanda fosse parcialmente estancada e o modelo fosse levado adiante, através de um ciclo de retroalimentação entre preços dos ativos financeiros e endividamento - em que a inflação dos ativos provia o colateral para a expansão dos empréstimos, que, por sua vez, conjuntamente com o relaxamento das condições para a concessão dos mesmos, sancionava preços de ativos cada vez mais elevados. Isso produziu tanto a bolha do mercado acionário, cujo fim ocorreu sem grandes sequelas no início dos anos 2000, quanto a bolha no mercado imobiliário norte-americano, com efeitos bem mais 
deletérios do que a primeira. Em outras palavras, "[r]ather than coming to a slow grinding halt, extended financial excess meant when the contradictions finally asserted themselves, the economy exploded in financial pyrotechnics." (Palley, 2012, p. 5).

$\mathrm{Na}$ Europa, a estagnação também foi adiada por desenvolvimentos do lado financeiro. Palley (2013a) menciona três "doses de adrenalina" que foram injetadas na economia e mantiveram essa tendência à estagnação, causada pelo desmonte das instituições e políticas do período pós-guerra, relativamente controlada. A primeira delas foi a expansão fiscal em virtude da unificação da Alemanha, que beneficiou toda a Europa por conta de ser a maior economia do continente. A segunda foi uma queda generalizada das taxas de juros ao longo dos anos 1990. E a terceira dose de adrenalina veio com a introdução do euro e a resultante convergência nas taxas de juros de longo prazo dos países da periferia da zona do euro em relação à Alemanha. Como consequência, esse duplo movimento de queda nos juros contribuiu para a formação de bolhas nos mercados imobiliários das economias periféricas.

Outros dois fatores que jogaram contra no caso da Europa e que continuaram deprimindo a demanda agregada, a despeito das contra tendências advindas do lado financeiro, foram: o modelo de crescimento alemão voltado para exportações, baseado em repressão salarial; e o próprio desenho institucional da zona do euro. O primeiro contribuiu para a formação de amplos desequilíbrios comerciais entre os países e para drenar a demanda em direção à Alemanha, além de estimular uma competição via redução salarial e redução dos padrões regulatórios e das proteções aos trabalhadores. Além disso, sabe-se que este país sempre foi mais um entrave do que um facilitador para a solução do segundo fator apontado acima, exigindo austeridade fiscal em troca de suporte financeiro. Por sua vez, a complexidade das questões institucionais envolvendo a zona do euro - tais como um novo modelo de Banco Central Europeu e uma maior integração fiscal entre os países - remete à necessidade de ações conjuntas por parte das autoridades e torna uma estagnação prolongada o cenário mais provável para a Europa (Palley, 2013a).

Diante do quadro esboçado acima, Palley não acredita que uma expansão fiscal e uma elevação da meta de inflação, como querem os autores do lado da demanda da tese de "estagnação secular", sejam suficientes para colocar as economias em uma trajetória de crescimento sustentado. Para ele, é necessário transformar completamente o paradigma que vigorou nas últimas três décadas e colocar no lugar, utilizando a metáfora da caixa, um regime onde as corporações e os mercados financeiros fiquem "dentro da caixa" e exercendo pressão sobre eles estejam: a) políticas de pleno emprego, uma vez que desemprego elevado significa relação mais fraca entre aumento dos salários e crescimento da produtividade; b) uma "globalização administrada" no lugar de uma "globalização corporativa", que tenha como meta puxar para cima os padrões de trabalho e ambientais em vez de promover uma "race to the bottom". Ademais, regimes de câmbio administrado e controle de capitais devem fazer parte da caixa de ferramentas de política econômica, a fim de evitar grandes desequilíbrios entre os países e evitar que os mercados financeiros obstaculizem ações 
dos governos no sentido de uma melhor distribuição de renda e de limitar o poder das corporações; c) a substituição de uma agenda antigoverno por uma relação mais equilibrada entre Estado e mercado, permitindo que aquele tenha capacidade de prestar bons serviços públicos, ao mesmo tempo que devolve ao investimento público o seu papel crítico na geração de empregos. De outro lado, essa agenda mais equilibrada entre Estado e mercado deveria restaurar e aprimorar a regulação sobre os mercados financeiros (limitando a especulação, aumentando a transparência e provendo os bancos centrais com instrumentos para garantir a estabilidade financeira) e sobre as corporações, de modo a desencorajar ações meramente especulativas e que vão contra os interesses de incremento da atividade naquele negócio; e d) a promoção de mercados de trabalho mais "solidários", por meio do fortalecimento dos sindicatos e a reconstituição de toda legislação de direitos e proteção aos trabalhadores mencionada anteriormente.

Caso não sejam tomadas medidas desse teor e, portanto, restaurado o ciclo do período pós-guerra, o processo gerador de demanda tende a continuar debilitado e, na ausência de novas bolhas no mercado financeiro, "stagnation is the logical next stage of the existing paradigma" (Palley, 2009, p. 27).

Assim, o keynesianismo-estruturalista de Thomas Palley se difere tanto do "keynesianismo" convencional quanto do pensamento pós-keynesiano, de Minsky e outros. Do primeiro pelo fato de enfocar no enfraquecimento do "processo gerador de demanda" em vez de quedas temporárias de demanda, em função de falhas no funcionamento do mercado. Do segundo, principalmente, por chamar a atenção para questões que passam relativamente despercebidas ante os aspectos financeiros, tais como o impacto da globalização produtiva sobre os salários - a literatura pós-keynesiana analisou mais detidamente os efeitos da globalização financeira em termos de estabilidade externa e interna das economias - e os desenvolvimentos institucionais do mercado de trabalho - como, para Keynes, o desemprego involuntário é resultado da insuficiência da demanda efetiva, determinada por questões sistêmicas, as consequências negativas da flexibilização na legislação trabalhista e da perda de representação dos trabalhadores ganharam menos proeminência dentro dessa literatura do que, por exemplo, os riscos sistêmicos decorrentes das alterações nas regras para o sistema financeiro.

Além disso, há uma diferença fundamental na abordagem do processo de financeirização das economias. Os autores pós-keynesianos geralmente o tratam como um "dreno" que subtrai recursos da economia e, por conseguinte, como um dos principais fatores responsáveis pela estagnação nas últimas décadas. Palley, por outro lado, reconhece que esse processo de aumento da importância e poder do sistema financeiro teve implicações negativas para a dinâmica econômica (pois, entre outras coisas, levou a mudanças nas estratégias das empresas, voltando-as para a elevação dos preços das ações e maior remuneração dos gestores), mas não está nele a chave para entender a estagnação dessas economias. Tendo, por outro lado, desempenhado um papel "funcional" para acumulação de capital, na medida em que o aumento dos preços dos ativos e do endividamento estiveram associados, 
embora com consequências desastrosas mais à frente, às fases de crescimento econômico.

Tal divergência interpretativa gera implicações nada desprezíveis. Para Palley, uma reforma do sistema financeiro, apesar de essencial, pode, ao retirar essa fonte de estímulo, agravar o problema da estagnação. Ele defende, portanto, que essa "re-regulação" do sistema financeiro seja acompanhada de reformas estruturais que recomponham o ciclo virtuoso do período pós-Guerra.

A explicação marxista (tema da próxima seção) tem uma visão similar no tocante à financeirização e sua "cura".

\section{Tradição marxista ligada à Monthly Review}

A segunda vertente de explicação para a estagnação dos países capitalistas avançados está bem mais assentada na história do pensamento econômico e remonta aos trabalhos clássicos de Kalecki e Steindl. Kalecki foi um dos autores dentro da tradição marxista que tratou da questão da realização da mais-valia (negligenciada por alguns desta tradição) e ofereceu, ao lado de Keynes, uma explicação para a insuficiência de demanda efetiva. Steindl, por seu turno, recolocou o problema no contexto de uma economia madura e viu nela uma tendência à estagnação.

Diferentemente da interpretação keynesiano-estruturalista, essa abordagem, desenvolvida por Sweezy e Baran na década de 1960, enxerga o marco dessa tendência à estagnação como muito anterior à introdução das políticas neoliberais no início dos $1980^{11}$. Para estes autores, o ponto fundamental é o processo de concentração e centralização de capital ocorrido no final do século XIX- início do século $\mathrm{XX}$, que deu origem à formação das grandes corporações. Tal processo somente viria a se consolidar plenamente, ao menos nos Estados Unidos, após a Segunda Guerra Mundial.

O significado dessa transformação é a ruptura da lógica do capitalismo concorrencial que vigorava até então. Para ficar mais claro, dividamos a história do modo de produção capitalista, como sugerido por essa literatura, em três grandes estágios. O primeiro ("mercantilismo") começou no século XVI e terminou no século XVIII. Essa é a fase da manufatura e do sistema fabril nascente, tipificada por Adam Smith em A Riqueza das Nações. A acumulação ocorria basicamente na agricultura, no comércio e na mineração. Nos termos dos esquemas de reprodução de Marx, o Departamento I (produtor de bens de capital) permanecia pequeno em

\footnotetext{
${ }^{11}$ A propósito, cabe acentuar que, dentro dessa perspectiva, o neoliberalismo é visto como a expressão de um novo estágio da acumulação de capital que ganha força aproximadamente nesse período, com a expansão e o predomínio dos mercados financeiros, denominada por Foster (2010) de monopoly-finance capital. Na verdade, esse estágio não é totalmente novo, sendo mais bem caracterizado como um estágio "híbrido". Pois, por um lado, mantém as características da fase anterior no que diz respeito ao caráter monopolista do capital e a tendência à estagnação, mas, por outro, introduz-se um elemento novo, qual seja, a "financeirização da acumulação de capital".
} 
termos absolutos e relativos, enquanto o Departamento II (produtor de bens de consumo) estava ainda limitado pelo trabalho manual (Foster e Mcchesney, 2012).

O segundo estágio ("capitalismo concorrencial”) é marcado pela Revolução Industrial na Inglaterra. $\mathrm{O}$ foco muda, então, para a construção da indústria moderna, e mais particularmente para a constituição do Departamento I, acompanhada de uma ampla infraestrutura de transportes e comunicações. Este é um período, enfatizam os autores, de intensa competição entre os capitais, onde a competição via preços tinha um papel central na regulação da atividade econômica.

O terceiro estágio ("capitalismo monopolista"), como indicado acima, começa no último quarto do século XIX e se consolida ao longo do século XX. As indústrias ficam, cada vez mais, na mão de poucas firmas oligopolistas, que têm controle sobre preços, investimentos e nível de produção ${ }^{12}$. Mais importante do que o crescimento e crescente interdependência entre os departamentos, que passam a responder rapidamente à demanda, a grande mudança nesse terceiro estágio de desenvolvimento capitalista foi a abolição da competição via preços como uma estratégia competitiva entre as firmas. Obviamente, isso não ocorreu imediatamente após a formação das grandes corporações, envolvendo um processo dinâmico entre os agentes envolvidos. Nem tampouco significou o extermínio da concorrência em si, mas tão somente a mudança na sua forma. A partir de então, o foco deixa de ser a "guerra de preços", forma característica de concorrência entre os capitalistas no estágio anterior, e passa a ser redução de custos e as estratégias de publicidade e propaganda (Foster e McChesney, 2012).

Nem por isso, contudo, o significado dessa mudança foi menor, dando origem a um capitalismo controlado por essas corporações e com um crescente excedente econômico (a lei da queda tendencial da taxa de lucro explorada por Marx é substituída, nessa fase, pela lei de um aumento crescente nos lucros). Entretanto, a contradição essencial desse novo estágio da acumulação é que esse crescimento dos excedentes não foi acompanhado por um aumento proporcional nas suas oportunidades de realização, seja via investimento ou consumo dos capitalistas; levando, na inexistência de fatores que suprissem essa insuficiência de demanda, a um excesso de capacidade instalada, baixo incentivo a novos investimentos e desemprego, em suma, estagnação.

Essa tendência foi controlada no período pós-Guerra (1945-1970) por fatores excepcionais, tais como: (i) a segunda grande onda de aumento do número de automóveis nos Estados Unidos, com a construção das estradas interestaduais e o crescimento dos setores ligados à indústria automobilística; (ii) a reconstrução das economias da Europa e do Japão; (iii) as duas guerras regionais travadas pelos

\footnotetext{
${ }^{12}$ Paralelamente ao desenvolvimento dessas fases da acumulação de capital, ou perpassando elas, há uma expansão geográfica do capitalismo. Porém, é somente no século XX, com o crescimento das corporações multinacionais, que os autores consideram a existência de um capitalismo verdadeiramente globalizado. Sweezy (1997) argumenta que, apesar de a globalização ter deixado suas marcas ao longo desse processo, ela não é a sua força motora, e sim, como sempre foi desde o início da história moderna, uma tendência expansiva inerente à acumulação de capital.
} 
Estados Unidos nesse período na Coreia e na Indochina; (iv) um aumento da atividade financeira (bancos, outras instituições financeiras, mercado imobiliário e seguros); (v) a ascensão dos Estados Unidos à posição de potência hegemônica, acompanhada pelo aumento do número de bases militares ao redor do mundo, bem como da ajuda financeira através do Plano Marshall; (vi) os regimes monetários e financeiros, associados à constituição do GATT, do FMI e do Banco Mundial, todos dominados pelos Estados Unidos, que resultaram em uma circulação mais livre dos capitais no mundo e o estabelecimento de regras comerciais para os países do Terceiro Mundo; e (vii) a formação de empresas multinacionais, constituindo importantes mecanismos de estratégias imperialistas (Foster, 1987).

No entanto, há uma assimetria fundamental entre as forças que levam o capitalismo à estagnação e os fatores que agem no sentido contrário. Enquanto as primeiras estão profundamente enraizadas na lógica de acumulação do capital monopolista, as contratendências são superficiais e "autolimitadas". Por exemplo, os gastos de guerra precisam de uma ameaça externa para se justificar; os esforços de venda e publicidade empreendidos por empresas (outro fator que enfraquece essa tendência à estagnação mencionado pelos autores) somente são válidos enquanto aumentarem as vendas das mesmas; os gastos governamentais sofrem oposição da classe capitalista, pois tendem a entrar na esfera privada de acumulação de capital; e as épocas de grandes inovações tecnológicas são raras e os efeitos destas, apesar de poderosos, também tendem a se esgotar com o tempo.

Como efeito, a estagnação voltaria a aparecer nos anos 1970 sob a forma de “estagflação". A saída adotada pelos governos da época, conforme já explorado na subseção anterior, foi o desmonte progressivo do estado de bem-estar social e a adoção de duras políticas para controlar a inflação. Mas o capital monopolista encontraria seu principal refúgio entre a onda de inovações financeiras e ativos exóticos que começaram a surgir nesse período, a exemplo do que havia ocorrido na década de 1920. Foi neste espaço de acumulação financeira que o excedente econômico descobriria oportunidades praticamente infinitas para sua realização.

Entretanto, como pontuado por Sweezy (1994), o crescimento que ocorre no setor financeiro a partir de então representou um acontecimento sem precedentes. O setor financeiro que sempre esteve, desde a época de Hilferding e Lênin, lado a lado com o capital industrial, e jogou um papel essencial no processo de concentração e centralização de capital que deu origem às grandes corporações, desde meados dos anos 1980 aproximadamente, sai de seu papel auxiliar ou coadjuvante no processo de acumulação de capital (que, de tempos em tempos, se autonomizava e resultava em crises financeiras no final de fases ascendentes dos ciclos econômicos) para o papel de protagonista nesse processo. Isto é, o centro de gravidade da acumulação de capital muda da esfera produtiva para os mercados financeiros. Ou, em outras palavras, o circuito do capital D-M-D' transmuta-se, simplificadamente, em D-D', prescindindo, portanto, da passagem pela esfera produtiva para sua realização.

Isso, claro, tem uma série de implicações não somente econômicas, mas também políticas e sociológicas. Grosso modo, o comando das grandes corporações 
muda dos conselhos de administração dessas empresas para os mercados financeiros. E o Estado, antes "servo" dos interesses da elite industrial ou do ramo de serviços, fica subjugado ao crescente poderio financeiro de Wall Street. Desse modo, não somente a alocação dos recursos do Estado tem que passar pelo crivo severo dos banqueiros, mas as políticas monetárias e regulatórias sofrem poderosa influência dos mercados financeiros ${ }^{13}$.

Esse processo se desenrola em número crescente de (e cada vez mais amplas) bolhas financeiras, desaguando, finalmente, na crise de 2007-2008 e na chamada Grande Recessão. Contudo, uma vez implementadas as políticas de resgate das instituições financeiras e ensaiadas iniciativas de regulação destas instituições, o capital financeiro volta à tona. Não somente pela sua capacidade de captura das instituições reguladoras, mas porque não há saída. Mesmo se implementadas políticas ativas de gasto público a solução seria apenas temporária. A contradição fundamental do capital monopolista, que é a desproporção entre a geração de excedente econômico e oportunidades de realização do mesmo, permanece viva, e impedindo o início de uma nova fase de crescimento. Portanto, estamos presos em o que Magdoff e Foster (2014) chamaram de "stagnation-financialization trap". Como quebrá-la de uma vez por todas? Através de uma transformação radical, possivelmente com a superação do modo de produção capitalista.

A curto prazo, é difícil imaginar que uma transformação assim ocorra. Se a possibilidade de um novo New Deal aparenta estar distante, o que dizer da superação do capitalismo? É claro que as condições se alteram (às vezes, em um curto espaço de tempo), e a própria estagnação, ajudada pelas políticas explosivas de cunho neoliberal, pode contribuir para criar as condições sociais necessárias para uma mudança radical. Mas como assinala Eric Hobsbawm (1988), em seu magistral epílogo da obra "A Era dos Impérios", a crença de que a história ruma em direção ao progresso desapareceu junto com o desenrolar do século XX. Após um século de guerras, revoluções, contrarrevoluções e crises (em maior quantidade do que em qualquer outro período da história) fica evidente, em nossa visão, que não há nada como "necessidade histórica" ou tendências inexoráveis, sempre dependendo o futuro das lutas sociais travadas.

Nas atuais circunstâncias, é desejável uma união de keynesianos estruturalistas e marxistas contra as políticas de austeridade e a destruição das instituições do estado de bem-estar social. As divergências entre eles terão início apenas em um segundo momento, relacionadas, entre outros aspectos, a diferenças interpretativas em relação à estagnação (os marxistas atribuem-na a tendências inerentes ao próprio sistema capitalista, ao passo que keynesianos estruturalistas a entendem como saldo de políticas econômicas e reformas institucionais equivocadas) e a concepções díspares em relação ao papel do Estado (não obstante o debate travado dentro do próprio marxismo a este respeito, encontra-se um maior ceticismo nessa linha de

${ }^{13}$ Ver Sweezy (1994) e Foster e Holleman (2010). 
pensamento do que entre keynesianos no que tange à possibilidade de ações transformadoras por parte do Estado).

Do ponto de vista teórico, uma aproximação poderia ser buscada para aprofundar o entendimento de ambas a respeito das relações entre as esferas monetária/ financeira e real da economia. Autores da vertente keynesiana tem se esmerado em desvendar os "ciclos financeiros" e a instabilidade trazida por eles para a economia real, mas deixam a desejar em uma compreensão mais acurada da acumulação de capital e suas tendências. O contrário pode ser dito em relação aos marxistas. Destarte, falta "apenas" construir as pontes.

\section{CONSIDERAÇÕES FINAIS}

À exceção dos headwinds de Gordon, todas as explicações abordadas situam o problema do lado da demanda. Mas a convergência entre elas se encerra praticamente por aí. Se, por um lado, as explicações convencionais tratam a insuficiência crônica de demanda como decorrentes de uma nova rigidez, a Zero Lower Bound (ZLB), por outro lado, a explicação keynesiano-estruturalista a considera resultado das políticas econômicas neoliberais e da destruição das instituições do pós-Guerra, enquanto a explicação marxista, apesar de não desconsiderar os impactos sociais negativos do neoliberalismo, situa o problema de um ponto de vista sistêmico, a saber, como consequência da tendência inerente ao capital de concentrar-se em unidades econômicas cada vez maiores.

No tocante às políticas econômicas propostas para solucionar essa situação, o "keynesianismo" convencional e o keynesianismo-estruturalista concordam na necessidade de uma política fiscal expansionista para estimular os investimentos privados. No entanto, a segunda vertente entende que essas políticas não são suficientes para recolocar as economias em uma trajetória de crescimento sustentado com distribuição de renda. Para isso, é essencial a reconstrução das instituições do pós-Guerra, que possibilitaram naquele período um crescimento do salário real em linha com a produtividade. Uma reforma ampla e radical do sistema financeiro também é bem-vinda, ainda que não seja condição indispensável para atingir o referido objetivo.

Os marxistas, por sua vez, são mais céticos em relação a uma saída dentro do sistema. Políticas de cunho progressista sofrem forte oposição da aliança de classes que se encontra no poder e, mesmo que fossem levadas a efeito, representariam um expediente provisório. Uma vez contraídos os gastos e flexibilizadas as regras, como tem ocorrido infalivelmente ao longo dos ciclos, a doença que acomete o sistema capitalista voltaria a se manifestar, levando a desemprego, estagnação salarial e crescimento nulo.

Não obstante as diferenças mencionadas, entendemos que uma maior aproximação entre as duas últimas correntes seria benéfica a ambas. 


\section{REFERÊNCIAS BIBLIOGRÁFICAS}

Backhouse, Roger E. e Mauro Boianovsky (2016) “Secular stagnation: The history of a macroeconomic heresy", The European Journal of the History of Economic Thought, 23(6): 946-970.

Baran, Paul A. e Paul M. Sweezy (1966) Monopoly Capital: An Essay on the American Economic and Social Order. New York: Monthly Review Press.

Bresser-Pereira, Luiz Carlos (2018) "Afinal, a estagnação secular do capitalismo?”, Revista Brasileira de Ciências Sociais, 33(96): 1-9.

Eggertsson, Gauti B. e Paul Krugman (2012) "Debt, Deleveraging, and the Liquidity Trap: A Fisher-Minsky-Koo Approach”, Quarterly Journal of Economics, 127 (3): 1469-1513.

Eichengreen, Barry (2014) "Secular stagnation: A review of the issues". In: Coen Teulings e Richard Baldwin, eds. Secular Stagnation: Facts, Causes and Cures. London: CEPR Press: 41-46.

Fogel, Robert W. (2005) "Reconsidering Expectations of Economic Growth After World War II from the Perspective of 2004", IMF Staff Papers, vol. 52, Special Issue: 6-14.

Foster, John Bellamy (1987) "What Is Stagnation?”. In: The Imperiled Economy: Macroeconomics from a Left Perspective. New York: The Union for Radical Political Economics: 59-70.

Foster, John Bellamy (2010) "The Age of Monopoly-Finance Capital”, Monthly Review, 61(9): 1-13.

Foster, John Bellamy e Hannah Holleman (2010) “The Financial Power Elite”, Monthly Review, 62(1): 1-19.

Foster, John Bellamy e Fred Magdoff (2009) The great financial crisis: causes and consequences. New York: Monthly Review Press.

Foster, John Bellamy e Robert W. McChesney (2012) The endless crisis: how monopoly-finance capital produces stagnation and upheaval from the U.S.A. to China. New York: Monthly Review Press.

Gordon, Robert J. (2012) "Is U. S. Economic Growth Over? Faltering Innovation Confronts the Six Headwinds", NBER Working Paper Series, No. 18315, August.

Gordon, Robert J. (2014a) “The Demise of U.S. Economic Growth: Restatement, Rebuttal, and Reflections”, NBER Working Paper series, No. 19895, February.

Gordon, Robert J. (2014b) “The turtle's progress: Secular stagnation meets the headwinds”. In: Coen Teulings e Richard Baldwin, eds. (2014) Secular Stagnation: Facts, Causes and Cures. London: CEPR Press: 47-60.

Hansen, Alvin H. (1939) "Economic Progress and Declining Population Growth", The American Economic Review, 29(1): 1-15.

Hobsbawm, Eric J. (1988[2011]) A era dos impérios, 1875-1914. São Paulo: Editora Paz e Terra.

Keynes, John Maynard (1936 [2007]) A Teoria Geral do Emprego, do Juro e da Moeda. São Paulo: Editora Atlas.

Kotz, David M. (2003) "Neoliberalism and the US Economic Expansion of the 1990s", Monthly Review, 54(11): 15-33.

Kotz, David M. (2009) "The Financial and Economic Crisis of 2008: A Systemic Crisis of Neoliberal Capitalism”, Review of Radical Political Economics, 41(3): 305-317.

Krugman, Paul (1998) "Its Baaack: Japans Slump and the Return of the Liquidity Trap”, Brookings Papers on Economic Activity, 29(2): 137-205.

Magdoff, Fred e John Bellamy Foster (2014) "Stagnation and Financialization: The Nature of the Contradiction”, Monthly Review, 66(1): 1-24.

Palley, Thomas I. (2009) “America's exhausted paradigm: Macroeconomic causes of the financial crisis and great recession", IPE Working Papers, No. 02/2009, November.

Palley, Thomas I. (2010) “The Limits of Minsky's Financial Instability Hypothesis as an Explanation of the Crisis”, Monthly Review, 61(11): 28-43.

Palley, Thomas I. (2012) From financial crisis to stagnation: the destruction of shared prosperity and the role of economics. New York: Cambridge University Press.

Palley, Thomas I. (2013a) “Europe's crisis without end: The consequences of neoliberalism run amok", IMK Working Paper No. 111, March. 
Palley, Thomas I. (2013b) “Gattopardo economics: The crisis and the mainstream response of change that keeps things the same", IMK Working Paper No. 112, April.

Palley, Thomas I. (2016) "Zero Lower Bound (ZLB) Economics: The Fallacy of New Keynesian Explanations of Stagnation", IMK Working Paper No. 164, January.

Rachel, Lukasz e Thomas D. Smith (2015) "Secular drivers of the global real interest rate", Bank of England Staff Working Paper No. 571, December.

Steindl, Josef (1952) Maturity and stagnation in American capitalism. Oxford: Basil Blackwell.

Steindl, Josef (1987) “Stagnation”. In: John Eatwell, Murray Milgate e Peter Newman, eds. The New Palgrave: A Dictionary of Economics. London: The Macmillan Press Limited: 472-474.

Summers, Lawrence H. (2014a) "Reflection on the New Secular Stagnation Hypothesis". In: Coen Teulings e Richard Baldwin, eds. Secular Stagnation: Facts, Causes and Cures. London: CEPR Press: 27-40.

Summers, Lawrence H. (2014b) "U.S. Economic Prospects: Secular Stagnation, Hysteresis, and the Zero Lower Bound”, Business Economics, 49(2): 65-73.

Summers, Lawrence H. (2015) "Demand Side Secular Stagnation”, American Economic Review: Papers \& Proceedings, 105(5): 60-65.

Summers, Lawrence H. (2016) "The Age of Secular Stagnation: What It Is and What to Do About It", Foreign Affairs, 95(2): 2-9.

Sweezy, Paul M. (1994) “The Triumph of Financial Capital”, Monthly Review, 46(2): 1-11.

Sweezy, Paul M. (1997) “More (or Less) on Globalization”, Monthly Review, 49(4): 1-4.

Taylor, Lance (2014) “Paul Krugman's 'liquidity trap' and other misadventures with Keynes”, Review of Keynesian Economics, 2(4): 483-89.

Taylor, Lance (2016) "The "Natural” Interest Rate and Secular Stagnation: Loanable Funds Macro Models Don't Fit the Data”. Disponível em: https://www.ineteconomics.org/research/research-papers/the-natural-interest-rate-and-secular-stagnation-loanable-funds-macro-models-dont-fit-the-data. Acesso em: agosto 2017.

Teulings, Coen e Richard Baldwin, eds. (2014) Secular Stagnation: Facts, Causes and Cures. London: CEPR Press. 